\title{
1 \\ Introduction: Theories of the historical fertility decline
}

\section{The historical fertility transition}

In the 19th and early 20th centuries, most European countries and English-speaking countries outside Europe experienced a demographic transition.

According to McDonald:

Demographic transition refers to the process whereby populations shift from regimes of high mortality and high fertility in approximate long-run equilibrium (zero population growth) to a new equilibrium at low levels of mortality and fertility. (McDonald 2001: 1)

Since the 1950s, many scholars have put forward theories to explain why and how the fertility transition occurred and considerable research has been undertaken to find evidence to support these theories. The European Fertility Project (EFP), for instance, which took place at the Office of Population Research at Princeton University during the 1960s and 1970s, undertook a vast amount of research into the 19th-century European fertility decline (Coale and Watkins 1986; Alter 1992).

The EFP considered that the fertility transition occurred in most European countries between 1880 and 1930, although the decline began earlier in France, from the late 18th century (Coale 1986; Cleland 2001). The project adopted a fairly conservative estimate of the timing of the decline, defining the start as the date from which marital fertility fell 10 
per cent below the previous plateau and never returned to that plateau (Coale and Treadway 1986). Using this measure, fertility declined in some countries in Europe from the 1880s (Belgium and Switzerland), in England and Wales in the early 1890s and in most other European countries around 1900. Many demographers, however, disagree with the EFP criterion and consider that the fertility decline started several years earlier. For instance, according to the EFP measure, the fertility decline began in Sweden in 1902 (Coale and Treadway 1986), whereas it is now generally agreed that it began about 20 years earlier, around 1880 (Bengtsson and Dribe 2014; Dribe and Scalone 2014).

Most scholars consider that the fertility decline began in England in the 1870 s and fertility fell from around the same period in other Englishspeaking countries (Woods 1987; Caldwell 1999). Marital fertility started to fall from about the late 1860s in the United States, from the 1870s in English-speaking Canada and New Zealand and from the 1880s in Australia (Coghlan 1903; Jones 1971; Ruzicka and Caldwell 1977; Caldwell 1999; Gauvreau and Gossage 2001; Hacker 2003). The Australian data suggest the timing of the fertility decline varied somewhat between the colonies, falling first in Victoria from the mid1870 s and from the 1880s in all other colonies except Western Australia (Jones 1971; Quiggin 1988).

\section{The fall of marital fertility in Tasmania}

The aim of this book is to examine the fall of marital fertility in Tasmania, the second settled Australian colony, in the late 19th and early 20th centuries. In this book, I use quantitative and qualitative data to examine when marital fertility fell, how it fell — that is, was the fall due to starting, stopping or spacing behaviours - and why it fell at this time. I examine how my findings support theories of why fertility fell during the fertility transition.

Total fertility consists of marital fertility and ex-nuptial fertility. In examining the historical fall in fertility, most demographers have concentrated on marital fertility. This is because ex-nuptial fertility was generally unplanned and unintended, whereas when married couples decided to limit their fertility, they made conscious decisions about their childbearing. In Australia in the late 19th and early 20th centuries, almost 
all births were within marriage. In New South Wales in 1891, for instance, 5.9 per cent of all births were ex-nuptial births (NSW Bureau of Statistics and Economics 1912).

In the final decades of the 20th century, some analyses were undertaken of the fertility decline in various parts of colonial Australia, as will be discussed in Chapter 2. However, about 20 years ago, a digitised database of 19thcentury Tasmanian births, deaths and marriage registration information became available for research purposes, enabling much larger and more complex studies of historical demographic events to be conducted (for example, Kippen 2002c). This is the first analysis of the historical fertility decline in Tasmania using this database.

I used the Tasmanian registration data plus many other sources to reconstitute birth histories of couples marrying in Tasmania in the second half of the 19th century-specifically, in 1860, 1870, 1880 and 1890. This provided me with an individual-level database (Van Bavel 2004b), which has enabled me to use both bivariate and multivariate methods in my analysis of the fertility decline.

While some qualitative analyses have been undertaken of the historical fertility decline in Australia (Hicks 1978; Quiggin 1988; Bongiorno 2012), the findings have not been placed in any theoretical context. In this book, I examine how the historical context of Australia, and of Tasmania specifically, and historical sources_-such as witness statements from the 1903 Royal Commission on the Decline of the Birth-Rate and on the Mortality of Infants in New South Wales, articles and items from the late 19th and early 20th-century Tasmanian newspapers and diaries of upper-class Tasmanian women-provide support for theories of fertility decline.

In the past five to 10 years, digitised sources, such as vital registration indexes and 19th and 20th-century Australian digitised newspapers, have become available on the internet and this has facilitated the task of reconstituting families and studying the social and economic conditions of the period. This is the largest study of reconstituted birth histories ever undertaken in Australia. Uniquely for Australia, this is the first study to examine the impacts of child mortality on fertility and to apply multivariate analysis. 


\section{Theories of the historical fertility decline}

Theories as to why marital fertility declined in Western Europe and English-speaking countries in the late 19th and early 20th centuries have been reviewed by several authors (for example, Cleland and Wilson 1987; Alter 1992; Hirschman 1994; van de Kaa 1996; Mason 1997; McDonald 2001; Abbasi-Shavazi et al. 2009; Bengtsson and Dribe 2014). These theories are often difficult to test and the evidence is sometimes contradictory. This chapter examines theories of the historical fertility decline and available evidence for these theories according to the following categories: demographic transition theory, diffusion theory, economic theories, secularisation, trends in infant and child mortality, increased accessibility of artificial methods of birth control and changes in women's roles and status in society and in the family. The chapter also examines theories about how fertility declined - that is, was it through changes in age at marriage, in birth spacing or in stopping having children before the end of the reproductive lifespan?

\section{Demographic transition theory}

According to demographic transition theory, mortality declined in the 19th century in Western Europe and English-speaking countries because of 'modernisation' (Notestein 1945: 39; 1983). The decline in mortality was followed by a decline in fertility, which was a 'response to drastic changes in the social and economic setting that radically altered the motives and aims of people with respect to family size' (Notestein 1945: 40). Industrialisation and urbanisation changed the roles of the family, there was growing individualism, greater opportunities for individual social and economic advancement, large families became more expensive to maintain and parents began to concentrate more on the wellbeing of the individual child. While fairly effective means of contraception had been known for many years, they were not widely used until families had the incentive to limit their fertility.

Findings from the EFP, however, called into question demographic transition theory, since the project found the fertility decline occurred at the same time in late 19th and early 20th-century Western and Eastern European societies that were at very different stages of economic and social development (Knodel and van de Walle 1979, 1986; Cleland and 
Wilson 1987). Economic and social development was measured by the following indicators: the percentage of the male labour force employed in agriculture, the percentage of the population in rural areas, the percentage of cities with more than 20,000 people and the percentage of illiterate people (Knodel and van de Walle 1979).

Demographic transition theory also states that a decline in infant and child mortality in a society is a necessary condition for marital fertility to decline (Freedman 1962; Preston 1978). The EFP findings, however, did not support this sequence, as they showed the relationship between infant mortality and fertility was not consistent (Matthiessen and McCann 1978; Knodel and van de Walle 1979; van de Walle 1986). In some countries, infant mortality declined before marital fertility; in others, the decline in marital fertility preceded the decline in infant mortality, while in others the two declines occurred around the same time (van de Walle 1986).

However, while rejected by the EFP, the demographic transition theory received renewed support from subsequent research (Schellekens and van Poppel 2012; Dribe et al. 2014). Studies on the fertility decline in two large German states, Bavaria and Prussia, using different statistical techniques to the EFP project on less highly aggregated geographic areas, concluded that economic and social factors played an important role in the fertility decline (Galloway et al. 1994; Lee et al. 1994; Brown and Guinnane 2002). More recent studies of the fertility transition in parts of Europe, Iceland, Canada and the United States also found that social and economic change was likely to have played a role in the fertility decline (Schellekens and van Poppel 2012; Dribe et al. 2014).

A re-examination of the findings of European historical studies on the relationship between infant mortality and fertility in the fertility transition and a new analysis of the fertility decline in Prussia also indicated there was a positive relationship between changes in infant mortality and changes in marital fertility (Galloway et al. 1998). A recent study of the fertility decline in Aranjuez, Spain, concluded that, in this locality, the improvement in 'child survival' was 'the key variable leading to fertility control' (Reher and Sanz-Gimeno 2007: 717). 


\section{Diffusion theories of the fertility decline}

The EFP concluded that the fertility decline began and spread within and between areas that shared similar cultural characteristics, such as values and languages, because knowledge and ideas about fertility control began to spread throughout these communities (Knodel and van de Walle 1979; Cleland and Wilson 1987). This occurred independently of changes in economic and social conditions. Thus, the diffusion of ideas and values about fertility control was the reason for the decline in fertility at this time.

Linguistic and cultural boundaries were very important in explaining the fertility decline (Cleland and Wilson 1987). An analysis of the decline in Belgian fertility in the late 19th century, for instance, showed that fertility declined earlier and more quickly in French-speaking than in Dutch-speaking communities, despite similarities in their socioeconomic characteristics (Lesthaeghe 1977). Even where Dutchspeaking and French-speaking communities were located adjacent to one another and were socially and economically very similar, the two communities were 'two obviously non-interacting demographic regimes' (Lesthaeghe 1977: 112).

The EFP found that various elite groups were the 'forerunners' of the fertility decline in Europe, with fertility control practised in some areas in Europe in the 18th century (Livi-Bacci 1986: 183). Diffusion theorists argue that, in general, the highest socioeconomic status families are the first to take up any innovative behaviour and are progressively followed by groups of lower socioeconomic status, with those of the lowest status the last to change (Rogers 1983). Thus, in 19th-century Western Europe, ideas and values about fertility control spread progressively from elites to the upper and middle classes and then to the working classes (Livi-Bacci 1986).

More recent studies of the fertility transition in parts of Western Europe, Canada and the United States have shown that the upper and middle classes were the first to limit their fertility, followed by the other classes (Schellekens and van Poppel 2012; Bengtsson and Dribe 2014; Breschi et al. 2014; Dribe et al. 2014; Vézina et al. 2014). Woods (1987), however, argues that although there were differences in fertility between the occupational classes in 19th-century England and Wales, the fertility decline occurred at the same time for all classes. This finding was disputed 
by Haines (1989), who, using the same dataset (the 1911 England and Wales fertility survey), argued that the upper and middle classes led the fertility decline and their fertility fell more rapidly than that of the other classes.

The EFP found that couples living in urban areas in Western Europe had lower fertility than those in rural areas well before the fertility decline (Livi-Bacci 1986). According to diffusion theory, new ideas generally originate in urban settings and ideas about fertility control and information about methods of control are likely to spread more quickly within a densely populated community (Galloway et al. 1994). In Western Europe, fertility was lower in urban areas than in rural areas at the start of the fertility decline and declined more rapidly once the decline was under way (Sharlin 1986). In Canada, also, during the fertility transition couples living in urban areas were more likely to limit their fertility than those living in rural areas (Gauvreau and Gossage 2001; Vézina et al. 2014). In Utah, in the United States, on the other hand, fertility declined at the same time in rural areas and in urban areas (Bean et al. 1990). No consistent relationship has been found between urban/rural location and the decline of marital fertility in England and Wales (Woods 1987; Szreter 1996).

A study of the fertility transition in Belgium shows the diffusion of information, and ideas about fertility control from one socioeconomic group to another was facilitated by geographic propinquity. An analysis of the 19th-century fertility decline in the town of Leuven found the working-class people who lived in districts alongside upper-class people were significantly more likely to control their fertility than those who lived in predominantly working-class districts (Van Bavel 2004c).

Some authors have suggested the relationship between fertility decline and socioeconomic status is more complex than the EFP argued and stress the importance of examining the spatial context when investigating the relationship between socioeconomic status and the fertility decline (Szreter 1996; Garrett et al. 2001; Dribe and Scalone 2014). Szreter (1996) concluded from his analysis of the 1911 England and Wales fertility survey that there were important regional differences within social classes regarding the timing of the fertility decline. This led him to the view that participation in a 'communication community' was more important than social class in explaining the fertility decline (Szreter 1996: 581). A reanalysis of these data, however, challenged his findings 
on the importance of social class, concluding that social class accounted for around two-thirds of the differences in fertility (Barnes and Guinnane 2012). A recent study of the historical fertility declines in Canada, Iceland, Sweden, Norway and the United States using microlevel data found that socioeconomic status 'was a very important factor in the fertility transition' even after controlling for spatial heterogeneity (Dribe et al. 2014: 146).

The relationship between education and fertility has been explained using diffusion theory. This relationship is well documented in developing societies in the 1970s and 1980s, with parents with high levels of education much more likely to use birth control and have lower marital fertility (Caldwell and McDonald 1982). Education encourages people to be receptive to new ideas and behaviour and gives them the skills to access new information (Cleland 2001). Studies of the fertility decline in Spain and Italy using survey data have found a relationship between literacy and fertility, with illiterate women having higher fertility than those who are able to read and write (Baizán and Camps 2007; Breschi et al. 2014). A study of the historical decline of fertility in Verviers, Belgium, however - using the husband's and wife's signatures on birth and marriage registers as the indicator of literacy-found no evidence of a relationship between literacy and fertility (Alter 1988). In contrast, studies of the fertility decline in Quebec, Canada, have found a positive relationship between parents' literacy and their fertility, but the authors attribute this relationship to the effect of the French-Catholic schooling system on parents' value systems (Gauvreau and Gossage 2001; Vézina et al. 2014).

Casterline (2001) suggests theories relating to how ideas and values about birth control and knowledge of methods were diffused are not well developed. However, in examining how information about birth control spread through 19th-century populations, many authors argue that written material in the form of books, pamphlets and articles in newspapers and magazines was an important source of information about birth control (Seccombe 1993; Caldwell 1999).

From the 1830s, pamphlets and books on birth control methods were published and circulated in Britain. These included Francis Place's 'Diabolical Handbills', Francis Carlile's Every Woman's Book (1828), Charles Knowlton's Fruits of Philosophy (1834), George Drysdale's The Elements of Social Science (1861), Henry Allbutt's The Wife's Handbook (1886) and Annie Besant's The Law of Population (1877) (see also Knowlton 1878; 
Besant 1887; Allbutt 1888; Branca 1975). The later publications were written in simple language, contained explanatory diagrams and were cheap to purchase. In the late 19th century, rising education levels made published information on birth control more accessible to a wider range of the population (Seccombe 1993).

Some authors consider that in the late 19th century, the publicity surrounding the trials of people distributing birth control information may have been a catalyst for the spread of birth control practices (Finch and Green 1963; Caldwell 1999; Hacker and Kippen 2007). From the 1870s, there were movements in the United States and in Britain to ban birth control books and pamphlets for reasons of obscenity. In England, for instance, in 1877, Annie Besant and Charles Bradlaugh were charged with obscenity for publishing and distributing Charles Knowles's pamphlet Fruits of Philosophy (Foster 1982). They were tried in the High Court and found guilty, but they appealed and the verdict was overturned. Prior to the trial, about 1,000 copies of Knowlton's book were sold every year (Bland 1995), but in the three-month period between the arrest and the conviction of Besant and Bradlaugh, around 125,000 copies were sold. Besant and Bradlaugh continued to publish the book despite being warned to stop. In the United States, however, many people were tried and imprisoned under the Comstock laws, enacted in 1873, which made it illegal to send literature about birth control methods or birth control devices through the mail (Brodie 1994).

Information about birth control methods was also disseminated in Britain through public lectures. After the Bradlaugh-Besant trial of 1877, huge crowds attended meetings to hear Besant and Bradlaugh speak about birth control (Bland 1995). In the early 1880s, Bradlaugh and Besant held meetings in many towns in the north of England advocating birth control methods and distributing literature (Elderton 1914). In the late 1880 s and 1890s, female members of the Malthusian League also spoke about birth control at public meetings and gave advice to working-class women (Bland 1995).

In the decades of the late 19th century and the early 20th century, artificial contraceptive devices and abortifacients were advertised extensively in newspapers and magazines in the United Kingdom (Elderton 1914; McLaren 1990). They were also advertised widely in the United States in the 19th century, although the Comstock Act had some impact on the circulation of such information (Brodie 1994). 
Doctors did not appear to be a major source of information about fertility control for their patients (Seccombe 1993). In Western Europe and the United Kingdom, letters and surveys about women's childbearing experiences in the late 19th and early 20th centuries indicate that doctors were unwilling to provide their working-class patients with information on how to stop further pregnancies. Contraception was not taught in medical schools and doctors were generally antagonistic to birth control devices, viewing them as injurious to health. Dr Henry Allbutt was struck off the medical register in 1887 for publishing The Wife's Handbook (Allbutt 1886; Foster 1982).

Seccombe (1993) argues that in 19th-century Britain and Western Europe, informal sources were more important than formal ones in spreading information about fertility control, with informal social networks important for lower-class families. 'Word of mouth was probably the principal means by which working-class people learned of contraceptives' (Seccombe 1993: 166). One working-class woman, writing to the Women's Guild in England in 1913-14 about her experiences of childbirth, explained that her friend had given her advice about contraception that had enabled her to limit the number of children she had (Llewelyn Davies 1978). A 1914 study by Elderton of working-class birth control practices in the north of England also stressed the importance of informal networks in spreading information about birth control methods:

One correspondent reports an afternoon gathering of women, many of whom were 'good church-workers' and the subject under discussion was not the legitimacy of restriction, but the most effective means of restriction. (Elderton 1914: 34)

Elderton's report also noted that many women obtained information about birth control methods and ways of procuring abortion from midwives.

\section{Economic theories of fertility decline}

In contrast to the diffusion theory of the historical fertility decline, which explains the processes by which fertility fell, economic theories try to explain why fertility fell-that is, what couples' motivations were for controlling their fertility. 
Economic demand theory asserts that the demand for children will fall when the cost of having another child is greater than the benefit of having that child (Easterlin 1975; Becker 1981; Becker et al. 1990). Fertility falls in conditions where the costs of children increase and exceed the social and psychological benefits of having an additional child (Abbasi-Shavazi et al. 2009). Becker (1981: 111) argues that, with economic development, the returns on investment in human capital (that is, education and training) increase and this shifts family expenditure 'towards quality and away from quantity' as each child becomes more expensive to rear. Additionally, in a society in which levels of human capital are high, the demand for children will be low because the 'opportunity costs' of having children are highthat is, married women experience higher returns from participating in the labour market than from childrearing (Becker et al. 1990).

The demand theory framework has also been applied by Caldwell, who argues that the introduction of mass education played a major role in the fertility decline in the late 19th century, because children became a cost rather than an economic benefit (Ruzicka and Caldwell 1977; Caldwell and Ruzicka 1978; Caldwell 1999). Once school attendance became compulsory, children became dependants and a burden on their parents rather than workers. Additionally, parents incurred expenditure in sending their children to school. Caldwell argues the decline in fertility was a response by parents to the change in the direction of 'net wealth flows' between parents and children - that is, wealth in terms of money, goods and services began to flow from parents to children, rather than from children to parents as previously (Caldwell 1976; Caldwell and Ruzicka 1978). A study of fertility decline in Ontario and Quebec found some support for Caldwell's theory in that families in Ontario whose children attended school all year had significantly lower fertility than other families (Gauvreau and Gossage 2001).

In support of economic demand theory, the timing of the fertility decline in working-class Britain and Western Europe has been linked to changes in the way children were treated in working-class families-that is, from being a 'net benefit' to a 'net cost' (Seccombe 1993). Before the fertility transition, large families were viewed as 'economically beneficial across the life-cycle', because older children could go out to work while younger children were dependent, and younger children became economically productive when parents were older and thus able to support their parents as they aged (Alter 1988: 164). In Victorian Britain even towards the end of the 19th century, working-class families could avoid sending their 
children to school and they were sent out to work at a relatively young age- sometimes as young as 10 or 11 years. However, in the Edwardian era, they were attending school regularly and were unable to go out to work to supplement the family income until they were considerably older. In Britain and Western Europe, respondents to surveys about childbearing experiences in the first decades of the 20th century said the main reason they wanted to stop childbearing was 'they could not afford any more children' (Seccombe 1993: 174).

A theoretical framework containing elements of both demand for and supply of children was developed by Easterlin (1975) for the analysis of marital fertility. This framework contains a number of determinants: the demand for children, which is determined by income and the cost of children relative to commodities; the 'subjective preference for children' compared with goods; the cost of fertility control, which includes attitudes towards fertility limitation, the availability of information about fertility limitation, the range of methods and their cost; and the 'potential output of children'-that is, the number of children a couple can potentially have, which depends on their natural fertility and whether or not their infants survive to adulthood (Easterlin 1975: 53-5). According to this model, couples are motivated to control their fertility when the 'supply' of children is greater than their 'demand' for children, but whether they change their behaviour by adopting fertility control methods depends on the 'costs' of fertility control (Easterlin and Crimmins 1985).

While demand theory focuses on a cross-sectional comparison of the costs and benefits of having children, another economic theory focuses on families' longer-term views of their economic future (Abbasi-Shavazi et al. 2009). According to this theory, parents began to limit their fertility because of their social and material aspirations for themselves and their children (Banks 1954; Lesthaeghe and Wilson 1986). As early as 1826, Thomas Perronet Thompson was writing about an Englishman's need to limit the number of children he had so he could support his family in the way that public opinion deemed socially acceptable (Thompson 1826). In the second half of the 19th century in English-speaking countries and many parts of Europe, there was increasing prosperity and more opportunities for social mobility because of industrialisation and a burgeoning of new occupations, particularly white-collar ones (McDonald 1974; Lesthaeghe and Wilson 1986). Education was viewed as an important factor in 
facilitating children's social mobility. In these circumstances, the rate at which families took up the practice of fertility control depended on their economic and social aspirations for their children.

The theory of parents' aspirations for their children explains why upper and middle-class families were the first to limit their fertility and were progressively followed by those of lower socioeconomic status, as discussed above (Banks 1954; Lesthaeghe and Wilson 1986; Seccombe 1993). Among the upper classes and the 'bourgeoisie', children were always viewed as a 'cost' and education was important for financial independence. In the 19th century, with industrialisation, workers of lower socioeconomic status began to develop aspirations for their children and saw education as the means by which these desires could be realised. In Britain, the upper strata of the working classes - the skilled workers — was the first of the working classes to limit their fertility, because of their desire for improved living standards for themselves and their children (Seccombe 1993). However, for parents in occupations such as farming, where children were important as workers and an economic benefit to their families, education beyond a basic level was not seen as an advantage. Consequently, these parents were less likely to take up fertility control.

Research into the relationship between fertility control and intergenerational social mobility has been very limited because of the availability of suitable data sources. However, Van Bavel et al. (2011) found that in Antwerp, Belgium, during the fertility transition, limiting family size was most effective as a 'defensive' strategy-for instance, when it was used by middle-class families to maintain the socioeconomic position of their children-rather than as an 'offensive' strategy. 'The effects all run in the direction of a large number of siblings increasing the odds of going down the social ladder' (Van Bavel et al. 2011: 338).

\section{Secularisation}

Some authors have argued that the spread of secularisation throughout Europe in the 19th century affected families' views on and practice of fertility limitation and was a necessary condition for the adoption of fertility control (Lesthaeghe and Wilson 1986). The basic tenet of secularisation was 'individual responsibility' and, according to this ethos, fertility, like many other aspects of life, was viewed as being under the individual's control rather than subject to 'God's will'. 
The EFP found a relationship between the speed of the fertility decline and the level of secularisation in late 19th and early 20th-century Western Europe (Lesthaeghe and Wilson 1986). The fertility transition was relatively homogeneous in Protestant communities, which tended to adapt to secularisation, while in Catholic communities, there was far more variation in the start and speed of the transition. Catholic communities that experienced secularisation early were among the first of any to adopt fertility control, while those where secularisation occurred much later were the last. A more recent paper looking at the impact of secularisation on the fertility decline in Veneto, north-eastern Italy, however, found that secularisation was not important at the start of the historical fertility decline but its impact grew in importance as the decline progressed (Caltabiano and Dalla Zuanna 2015).

Many other studies have found that, in most Western European countries and in Canada during the fertility decline, religious groups such as orthodox Protestants and Catholics who were 'traditional' in outlook had higher fertility than the rest of the population who were more 'liberal' or 'modern' (Gauvreau and Gossage 2001; Van Bavel and Kok 2005; van Poppel and Derosas 2006). Jews had the lowest fertility of all religious groups and were among the 'forerunners' of the fertility decline (Livi-Bacci 1986).

Some authors have argued that the specific practices of some religious groups may have facilitated the adoption of fertility control. Van Poppel et al. (2012) suggest that in Europe, Calvinism, with its emphasis on the importance of reading the scriptures, led to high levels of literacy among its followers. Education gave them access to ideas and information about fertility control and encouraged them to take control over this aspect of their lives.

\section{Infant and child mortality}

As discussed above, demographic transition theory posits a relationship between infant and child mortality and fertility at the societal level. Four main theories have also been put forward to explain the relationship between infant and child mortality and fertility at the individual level: physiological, insurance, replacement and societal (Preston 1978; van de Walle 1986). 
The 'physiological' relationship between infant mortality and fertility refers to the relationship between breastfeeding and fecundity. There is considerable evidence to show that when a child dies in infancy, a woman no longer avoids conception through breastfeeding and the space between the birth of the child who died and the subsequent child is reduced, leading to higher fertility (Knodel 1978, 1982; Wrigley et al. 1997). Knodel (1982), for instance, has shown that in several areas in pre-industrial Europe, birth intervals were shorter when the previous child had died than when the child survived, except in areas where breastfeeding was not common practice. However, he estimated that a substantial fall in infant mortality would result in only a small decline in fertility solely through the physiological mechanism, even in areas where breastfeeding was common and prolonged.

The 'insurance' relationship applies in a context of high infant mortality, in which people have as many children as possible because of their perception of the risk of their children dying. In the 'replacement' relationship, on the other hand, parents have a child to replace an infant or child who has died. Both theories imply that parents make a conscious choice to have a certain number of children or to have another childthat is, they imply a notion that parents are conscious of the ability to control their births (Knodel 1978; Preston 1978; van de Walle 1986).

Evidence for the 'replacement' effect of infant mortality on fertility was found by Knodel (1978) in his analysis of child mortality and fertility among couples in 14 German villages who married during the 18th and 19th centuries. Comparing cohorts who did not control their fertility with those who practised fertility control, Knodel concluded that families were making efforts to replace children who died in periods when family limitation had become established. Several other studies of countries in Western Europe have also found evidence for the replacement effect (Alter 1988; Alter et al. 2010; Schellekens and van Poppel 2012; Breschi et al. 2014; Vézina et al. 2014). Only a 'relatively modest' replacement effect, however, was found for the United States at the turn of the 20th century (Haines 1998: 244).

Knodel's study (1978) also found evidence for the insurance effect in that the experience of infant and child mortality within an individual family had an impact on that family's efforts to reduce their fertility. Even in a period when the general level of infant mortality remained relatively high, couples whose children survived were the most likely to adopt 
fertility control, while experiencing child mortality seemed to deter couples from efforts to limit their fertility. Haines (1998) also found a relatively strong insurance effect for the United States at the end of the 19th century. Another study of the fertility transition, in the Netherlands, however, found the replacement effect declined as the number of infant and child deaths increased (Schellekens and van Poppel 2012). Schellekens and van Poppel's analysis shows that the more deaths a family had, the less likely they were to have another birth, casting doubt on the insurance effect of infant mortality on fertility.

Recent research on the fertility transitions in Spain and the Netherlands has found that replacement/insurance effects can vary by socioeconomic status and, in the Netherlands, by religious affiliation (Reher and Sanz-Gimeno 2007; van Poppel et al. 2012). In the Netherlands, for instance, the number of surviving children more strongly affected parity progression ratios for the elite, middle classes and skilled workers than for other occupational groups, and more for liberal Protestants than for other religious groups (van Poppel et al. 2012). In both the Netherlands and Spain, the number of surviving children also affected birth spacing, with birth intervals longer at any given parity, the higher the number of surviving children.

Preston (1978) suggests the replacement strategy may be related to the sex of the child who dies - that is, if the parents desire a certain number of sons and the child who dies is female, they may not make efforts to 'replace' this child. Studies of fertility in Utah (Bohnert et al. 2012) and in Germany (Sandström and Vikström 2015) in the late 19th and early 20th centuries have shown families were more likely to progress to the next birth if they had only or mostly daughters. Alter et al. (2010), on the other hand, found no such relationship between sex composition and fertility in Sart in Belgium in the 19th century.

The societal strategy in relation to infant mortality and fertility refers to situations in which social norms around nuptiality or breastfeeding ensure that fertility is kept in equilibrium with mortality (Knodel 1978). For example, consistent with theories of demographic transition, scholars have argued that fertility declines because of the pressure of an increasing population due to the decline in mortality (Matthiessen and McCann 1978). In these circumstances, couples are pressured into marrying later, to limit the number of children they will have to rear. Alternatively, in societies with high infant mortality, men and women were encouraged to 
marry young so they could start their childbearing early (Wrigley 1978). The EFP's analysis of the patterns of nuptiality and child mortality, however, found no relationship between nuptiality and infant mortality (van de Walle 1986).

Infant mortality does not simply affect fertility; fertility can also affect infant mortality. Scholars generally agree the relationship between infant mortality and fertility is a two-way one, with higher fertility leading to higher infant mortality (van de Walle 1986; Bean et al. 1992; Haines 1998). A Swiss report published in 1878 , for instance, states that medical doctors concluded that repeated pregnancies were the primary reason for high infant mortality, because mothers of high parity were weak and gave birth to unhealthy babies (Switzerland 1878, in van de Walle 1986). A study of high fertility and high infant mortality in Utah also argued that children born at high parities were at risk because of competition for resources from their siblings and because of infectious disease (Bean et al. 1992). Other scholars argue that prior to the fertility decline some babies at high parities were unwanted and their parents let them die through neglect (Scrimshaw 1978). Knodel and van de Walle (1979: 230) cite the literature of the time that shows that 'concealed infanticide' or 'infanticide by neglect' was common in most of Europe before the fertility decline. Infant mortality thus may have declined when married couples began to limit the size of their families, because they were less likely to have babies at higher parities who were at greater risk of dying during their first year of life.

\section{Increased accessibility of artificial methods of contraception}

The greater availability of artificial methods of contraception has been put forward as a reason for the decline in fertility during the late 19th century (Caldwell 1999). However, there is little written evidence from the period of the extent to which these birth control methods were used in Western Europe and in English-speaking countries other than Australia.

Histories of contraception indicate the practice of contraception and the methods used can be traced back thousands of years (Finch and Green 1963; Himes 1963). References to one of the oldest methods of contraception, coitus interruptus (withdrawal), can be found in the Book 
of Genesis in the Old Testament of the Bible, and homemade pessaries made of mud were used by the Egyptians thousands of years ago (Finch and Green 1963). Some authors argue that, prior to the Western European fertility decline, fertility was restricted mainly by forms of behaviour such as prolonged breastfeeding and/or periodic separation of spouses for economic reasons (Knodel and van de Walle 1979; Coale 1986; Cleland and Wilson 1987). Knodel and van de Walle (1979) claim many people did not know about coitus interruptus and its use was not widespread, but Santow (1995) argues that there is strong evidence that coitus interruptus was used by the general population in pre-transitional societies to increase the spacing between births. Some authors put forward the view that prior to the fertility decline artificial forms of contraception, such as condoms, were associated with immorality and were not sanctioned within marriage (Cleland 2001).

Birth control measures were not used extensively until the second half of the 19th century, since there was no effect on the general level of fertility, but some small populations, such as the Italian elite, adopted birth control measures early on (Livi-Bacci 1986). Although we do not know what methods were used, books and pamphlets published by the Freethinkers in Britain in the 1830s, such as Knowlton's Fruits of Philosophy (1878), described artificial methods of contraception, such as the condom, the sponge and douching with a syringe, as well as coitus interruptus.

From the late 19th century, artificial contraceptive devices were made more cheaply and in larger quantities (Finch and Green 1963; Himes 1963). Condoms and pessaries (such as the French Pessaire Preventif) had become more reliable from the 1840s, with the development of a technique for vulcanising rubber (Himes 1963; Bongiorno 2012). In 1880, London chemist Walter Rendell developed a pessary made of quinine and cocoa butter to meet the needs of the poor women in his district (Finch and Green 1963). Rendell's pessaries were so successful that, in 1886 , he began to manufacture them on a large scale and was soon exporting them. A reverse-current syringe was introduced in the 1880s that improved the reliability of douching (Besant 1887). The 1887 edition of Annie Besant's The Law of Population contains advertisements for the 'India Rubber Check Pessary', the 'Improved Vertical and Reverse Current Syringe' and 'Rendell's Soluble Pessaries (Besant 1887: 47-8). 
The spread and acceptance of ideas about birth control resulted in a greater demand for contraceptives, which led to them becoming available in more 'respectable outlets', such as chemist shops (pharmacies) (McLaren 1990; Caldwell 1999). In Britain in the later decades of the 19th century, contraceptives were also sold by mail through advertisements in newspapers and magazines, and peddled door to door in villages and working-class neighbourhoods (McLaren 1990).

As noted, advertisements for abortifacients were prevalent in the English newspapers in the late 19th and early 20th centuries. It is not possible to tell whether abortions increased during this period, but Elderton (1914) argues that abortion was a common practice by the early 20th century and her report contains numerous references to various drugs used by working-class women in the north of England to procure abortions. A report in the British Medical Journal of 1899 refers to the 'pestilent traffic in so-called abortifacients' (BMJ 1899: 110). Several authors argue that the number of abortions for married women increased markedly across the Western world during the later part of the 19th century (McLaren 1990; Accampo 2003, citing Sohn 1996).

It is a commonly held view that coitus interruptus was the most common form of birth control used during the historical fertility decline (McLaren 1990; Seccombe 1993; Szreter et al. 2003). Szreter (1996: 393), however, considers that, in England and Wales before World War I, abstinence'reduction in the frequency of intercourse'-was the main method of reducing marital fertility. Szreter (1996: 420-1) argues that in British society withdrawal was a type of sexual abstinence, since he considers both methods are about 'sexual self-restraint'.

Many authors claim contraceptive appliances were too expensive for widespread use, their supply was low and there was hostility towards their use (McLaren 1990; Szreter 1996). McLaren (1990) argues that, although artificial contraceptives were available in the late 19th century, there is little evidence they were used widely. Brodie (1994) points out that this conclusion does not seem logical, since it is unlikely there would have been such a supply of information on contraceptive methods and contraceptive products for sale if there was only limited demand.

Evidence as to the type of birth control used during the historical fertility transition is scarce and, where available, is based on studies of highly unrepresentative populations. Mosher's survey of 47 American college- 
educated women undertaken around this time found a variety of methods was used to prevent conception: artificial contraceptive appliances as well as withdrawal and abstinence, with douching being the most common (MaHood and Wenburg 1980).

\section{Changes in women's roles and status in society and within the family}

Historical demographers have often ignored women's roles and their changing status in the public and private spheres as explanations for the 19th-century fertility decline (McDonald 2000). However, a few scholars have argued that attention should be paid to 'those cultural features that determine the status of women and their ability to assert their own wishes regarding childbearing' (Knodel and van de Walle 1979: 240). Seccombe (1993: 168) argues that 'women were the driving force behind family limitation', because they bore most of the burden of pregnancy, childbirth and child care. In Britain and Western Europe, surveys and letters from working-class women who underwent childbearing in the late 19th century and the first two decades of the 20th century show many women were motivated to adopt fertility control because of health concerns (Llewelyn Davies 1978; Seccombe 1993). They recounted difficult pregnancies and horrific experiences in confinement, which made them dread having more children.

Some authors argue that it should be impossible to study fertility transition without considering the part played by changing power relations between husbands and wives (Folbre 1983; McDonald 2000). McDonald (2000) has characterised power relations in the family as a component of 'gender equity', which is itself a characteristic of a society's gender system. The gender system is 'the socially constructed expectations for male and female behaviour that are found (in variable form) in every known human society' and applies to both the public and the private spheres (Mason 1997: 158). In societies with high fertility, for example, women experience 'gender inequity' in the private sphere (the family) when they are dissatisfied with the 'constant round of childbearing and childrearing imposed by spousal, familial, and societal expectations' (McDonald 2000: 428). In societies undergoing fertility transition, it is possible to have gender equity in the private sphere (the family), but not the public sphere (wider society), and vice versa. 
According to McDonald (2000), gender equity within the family is a necessary condition for fertility to decline and is facilitated through women's education. Not only do educated women become receptive to new ideas, but also education improves their autonomy and power within the family (Breschi et al. 2014). As noted above, studies of the fertility decline in Europe have found that more educated women were more likely to control their fertility.

Some authors have noted the importance of gender equity in the family as an explanation of the fertility decline in late 19th-century Britain and Western Europe. Szreter (1996), for instance, regards the difference in power relations between husbands and wives as one explanation for the low fertility of textile workers compared with the very high fertility of mining families in late 19th-century England. He argues that, among textile workers, relations between husbands and wives were relatively equal because of the wife's income and employment outside the home. In contrast, men had the power within mining families, because miners had high wages and their wives did not work outside the home.

The power relations between husband and wife may be affected by the difference in their ages and this may impact on their fertility preferences and use of contraceptive methods (Casterline et al. 1986). The association between a couple's fertility and the difference in age of the husband and wife is difficult to disentangle. Wives or husbands who are older than their spouse may have more influence on the couple's fertility behaviour (Tsuya et al. 2010), but their fecundity may be lower because of their age (McDonald 1984; Casterline et al. 1986). Studies of fertility in some areas of 19th-century Western Europe have found that couples among whom husbands were six or more years older than their wives had significantly lower fertility than couples among whom the wife was up to five years younger, but there were no significant differences where a wife was older than her husband (Feng et al. 2010). A study of the fertility transition in Alghero, Sardinia, however, found no significant differences in fertility according to the age difference between husband and wife (Breschi et al. 2014).

The feminist movement in Britain was viewed as important in influencing women to adopt birth control methods. Although feminism was primarily a middle-class movement in 19th-century Britain, feminist ideas had spread to working-class women by the early 20 th century and strengthened these women in their decision to limit their families (Seccombe 1993). 
Letters from working-class women about their childbearing experiences sent to the Women's Cooperative Guild just before World War I show many women had adopted a feminist position on several issues (Llewelyn Davies 1978).

The two methods scholars have put forward as the main methods of birth control used during the historical fertility decline-withdrawal and abstinence-are both within the control of men. McDonald and Moyle (2018) argue that women played an important role in the fertility transition and female methods of contraception were more important in Britain and Western Europe than many scholars have acknowledged.

Birth control pamphlets published and distributed in Britain were directed to women and recommended female methods of contraception, some of which could 'be used by the woman without inconvenience or knowledge of the husband' (Allbutt 1888: 49). Female contraceptive appliances and abortifacients were advertised and sold widely in Britain and the United States. Women in England actively sought information on birth control by attending lectures on the topic; some of these lectures were for 'women only' (Elderton 1914; Bland 1995). As noted previously, women had an important role in spreading information about methods of contraception through their informal networks.

\section{Models of fertility decline: 'Adjustment' or 'innovation' or both}

Since the middle of the 20th century, there has been an ongoing debate in historical demography as to whether the fertility decline was caused primarily by 'adjustment' to new social and economic conditions or by 'innovation' - that is, the diffusion and acceptance of innovative ideas and behaviours (Carlsson 1966; Cleland and Wilson 1987). It is now generally agreed, however, that the 'two sets of explanations are complementary, not competing' (Casterline 2001: 3). As McDonald (2001: 1) concludes, 'both adaptation and innovation are necessarily involved because people cannot change their behaviour without the necessary knowledge (innovation) nor do they do so without reason (adaptation)'. This reflects Coale's three major preconditions for a decline in marital fertility: 
Fertility must be within the calculus of conscious choice ... perceived social and economic circumstances must make reduced fertility seem advantageous to individual couples ... [and] effective techniques of fertility reduction must be available. (Coale 1973: 65)

Cleland (2001: 45) has proposed a 'blended' version of innovationdiffusion theory: 'Under the blended theory, the engine of demographic change is the structural transformation of societies, and diffusion is the lubricant.'

\section{How did fertility decline: Starting, stopping or spacing?}

There has been a major debate among demographers as to the extent to which fertility declined in the late 19th century through changes in 'starting', 'spacing' or 'stopping' behaviours (Okun 1995). Most of the debate has concerned the relative importance of 'stopping' and 'spacing' behaviour, which relates to the debate about the importance of the 'innovation' theory versus the 'adjustment' theory (van Poppel et al. 2012). 'Stopping' is viewed as an innovative form of behaviour that incorporates ideas that were unthinkable in pre-transition societies (Knodel and van de Walle 1979; Coale 1986; Cleland and Wilson 1987). 'Spacing' behaviour, on the other hand, is viewed as an extension of behaviour that was practised before the fertility decline, but became a way by which couples adjusted to new economic and social conditions during the decline (Anderton and Bean 1985; Santow 1995; Szreter 1996; Van Bavel 2004a; Van Bavel and Kok 2004).

The younger a woman is at marriage, the longer are her potential childbearing years (Wrigley et al. 1997). Scholars have argued that the timing of marriage- either delaying marriage or encouraging couples to marry earlier-was a fertility strategy for many centuries in Western Europe and English-speaking societies (McDonald 1981). In the early 19 th century, Malthus (1798) viewed late marriage as a preventive check on population growth and suggested people exercise 'moral restraint' and delay their marriage to curb fertility. Although theories about the relationship between marriage and fertility are primarily applied to pre-transition societies (Freedman 1963), some authors have claimed it also applied to some societies during the 19th-century fertility decline (Spengler 1968, cited in McDonald 1981; Matras 1965; Ruzicka and Caldwell 1977). McDonald (1981, 1984), however, argues that in both 
pre-transitional and transitional societies, the timing of marriage relates to economic, social and psychological factors, not to fertility preferences. In both pre-transitional and transitional societies, people married late so they would be in a better economic position to marry, rather than with the intention of curtailing their fertility. In the past 25 years, comparatively little attention has been paid to 'starting' behaviour in analyses of the 19th-century fertility decline in Western Europe and English-speaking countries. More recent studies of marriage in parts of Western Europe, Japan and China, however, support McDonald's view, finding that the risk of marriage in pre-transitional and transitional societies was influenced by socioeconomic status, household context, and local economic and demographic conditions' (Lundh and Kuroso 2014: 8).

In the mid-20th century, an influential group of demographers argued that, in late 19th-century Western Europe, couples began to deliberately limit their fertility through 'stopping' behaviour (Henry 1961; Coale 1986). This was an entirely new behaviour that was taken up to such an extent it initiated the fertility decline (Knodel and van de Walle 1979). According to this theory, first put forward by Henry (1961), couples use contraceptive methods - such as withdrawal, artificial methods or abortion-to avoid having more births after they have had a certain number of children and have decided they do not want any more. Henry contrasted this with behaviours such as prolonged breastfeeding, which increased birth intervals but are not parity related. Birth-spacing strategies can be used after any parity, including the first, and couples do not change their behaviour once they have reached a specific family size. Henry termed fertility that is deliberately controlled through 'stopping' at a specific parity as 'controlled fertility' and fertility where people practise non-parity-limiting behaviours as 'natural fertility'.

Coale (1986: 9) argues that fertility fell in Western Europe because of a change from 'spacing' behaviour to 'stopping' behaviour, with couples changing from non-parity-specific fertility-limiting behaviours to parityspecific limiting behaviours. Some authors have interpreted the theory of 'stopping' behaviour to mean that parents have in mind a preferred family size - that is, 'they become conscious of a desirable size of the family and set for themselves a target number of children, which they do not want to exceed' (van de Walle 1986: 205). Neither Henry nor Coale, however, specifically introduced the concept of a 'desired family size' into their theory, arguing instead that parents proceeded to have children until they decided they had as many as they wanted. While this may not 
seem an important distinction, as shown in the quantitative analysis, it has implications for identifying stopping and spacing behaviours in birth patterns.

Other demographers have argued that deliberate birth spacing-that is, intentionally lengthening the time between births early in marriageplayed an important role in the fertility decline (Anderton and Bean 1985; Bean et al. 1990; Santow 1995; Szreter 1996; Hionidou 1998). Analyses of fertility in 19th-century Utah show that stopping behaviour was an important fertility control strategy during the fertility decline, but birth spacing was also used as a strategy to limit fertility (Anderton and Bean 1985; Bean et al. 1990). Studies of populations in parts of Western Europe have shown that some families used spacing behaviour to control their fertility prior to the fertility decline, particularly in times of economic stress (Van Bavel 2004a; Dribe and Scalone 2010; Tsuya et al. 2010; Van Bavel and Kok 2010; Kolk 2011).

Nowadays, as with the associated 'innovation/adaptation' debate, most scholars agree that both stopping and spacing behaviours played a part in the 19th-century fertility decline, but the extent to which these behaviours were responsible for the decline within a society is a matter for investigation (van Poppel et al. 2012).

\section{The use of theories in this book}

In this book, I examine how findings from the quantitative and qualitative analysis of the fertility decline in Tasmania support the various theories outlined in this chapter and how they compare with findings from studies of Western Europe and other English-speaking countries. In the qualitative analysis, I pay particular attention to areas where the quantitative evidence is not available - that is, how ideas and values about fertility control and knowledge of methods were diffused; what methods of contraception were used during the fertility decline; and what the role of women was in the decline. 
This text is taken from Australia's Fertility Transition: A study of 19th-century Tasmania, by Helen Moyle, published 2020 by ANU Press, The Australian National University, Canberra, Australia.

doi.org/10.22459/AFT.2020.01 